\title{
Mobile communication (2G, 3G and 4G) and future interest of 5G in Pakistan: a review
}

\author{
Muhammad Saqib Iqbal ${ }^{1}$, Zulhasni Bin Abdul Rahim², Syed Aamer Hussain ${ }^{3}$, Norulhusna Ahmad ${ }^{4}$, \\ Hazilah Mad Kaidi ${ }^{5}$, Robiah Ahmad ${ }^{6}$, Rudzidatul Akmam Dziyauddin ${ }^{7}$ \\ ${ }^{1,2,4}$ Malaysia-Japan International Institute of Technology (MJIIT), Universiti Teknologi Malaysia (UTM), Malaysia \\ ${ }^{3,5,6,7}$ Razak Faculty of Technology and Informatics, Universiti Teknologi Malaysia (UTM), Malaysia
}

\begin{tabular}{l} 
Article Info \\
\hline Article history: \\
Received Oct 13, 2020 \\
Revised Mar 23, 2021 \\
Accepted Apr 11, 2021 \\
\hline
\end{tabular}

\section{Keywords:}

$5 \mathrm{G}$

IoT

Mobile Adoption

Mobile communication

\begin{abstract}
The use of mobile communication is growing radically with every passing year. The new reality is the fifth generation $(5 \mathrm{G})$ of mobile communication technology. 5G requires expensive infrastructural adjustment and upgradation. Currently, Pakistan has one of the most significant numbers of biometrically verified mobile users. However, at the same time, the country lags incredibly in the field of mobile internet adoption, with just half of the mobile device owners avail broadband subscription. It is a viable market with a large segment yet to be tapped. With the advancing progression in Pakistan towards the internet of things (IoT) connectivity, i.e., solar-powered home solutions, smart city projects, and on-board diagnostics (OBD), the urgency for speed, bandwidth and reliability are on the rise. In this paper, Pakistan's prevalent mobile communication networks, i.e., second, third and fourth generation $(2 \mathrm{G}, 3 \mathrm{G}$ and $4 \mathrm{G})$, were analyzed and examined in light of the country's demographics and challenges. The future of 5G in Pakistan was also discussed. The study revealed that non-infrastructural barriers influence the low adoption rate, which is the main reason behind the spectrum utilization gap, i.e., the use of $3 \mathrm{G}$, and the $4 \mathrm{G}$ spectrum is minimal.
\end{abstract}

This is an open access article under the CC BY-SA license.

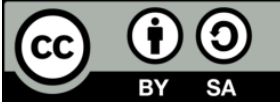

\section{Corresponding Author:}

Zulhasni Bin Abdul Rahim

Malaysia-Japan International Institute of Technology (MJIIT)

Universiti Teknologi Malaysia (UTM)

54100 Kuala Lumpur, Wilayah Persekutuan Kuala Lumpur, Malaysia

Email: zulhasni@utm.my

\section{INTRODUCTION}

Every year the use of mobile communication rises dramatically. It has become essential and even commodities everywhere [1]. The year 1895 laid the foundation for mobile communication. It has evolved vastly over time since then [2]. A wireless networking technology, i.e. complex spectrum connectivity, gives unlicensed users a remarkable ability to make use of frequency bands opportunistically [3]. Mobile communication is leading the current century with unmatched aggressive growth [4]. To accumulate this massively rising data and provide similar service quality to all users, higher bandwidth utilization, reliability, and higher connectivity are required [5]. Spectrum crisis and high energy consumption are the main challenges for 4G. Mobile networking technology's latest development is the fifth generation (5G) [6] which is expected to deal with all the expected growing demands. Researchers anticipate the deployment of 5G networks beyond 2020 [7]. Embracement of 5G networking is supposed to address the currently faced problems adequately [8]. However, with all these pressing expectations, it requires extensive infrastructural 
modifications [9] and up-grading the current infrastructure, requiring extensive costs. A significant paradigm shift is vital in this regard [9].

In Pakistan, telephone density (teledensity) is as high as 74\% [10]. It is around $96 \%$ in urban areas and $32 \%$ in suburban and rural areas [11]. It means that there are over 150 million biometrically verified mobile users in the country. Pakistan arrived late in this field but since the licensing and adoption of 3G/4G in 2014 [12]. However, wireless broadband penetration is merely 27.2\% [10] as connectivity and reliability are overwhelming issues, even in urban areas [13]. Barriers like affordability [11], unemployment [14], and illiteracy [15] remain the core issues for adoption despite the coverage opportunities. 5G will surely add its bit to all these barriers. It was anticipated that by $2019,3 \mathrm{G} / 4 \mathrm{G}$ would capture $58 \%$ of the mobile market, overtaking the $2 \mathrm{G}$ subscriptions [12] however, $2 \mathrm{G}$ still dominates $59 \%$ of the market whereas $3 \mathrm{G}$, and $4 \mathrm{G}$ only has $27 \%$ and 14\% market share respectively [16]. The long-term solution for improving latency is to boost peering locally and with regional internet service providers (ISPs) [17]. To enhance the communication capacity, 5G may utilize the spectrum in millimetre-wave (mm-Wave) bands [18] that will require real disruption in both system architecture and component design [19].

IoT is another pressing challenge [20]. In recent years, the Internet has been linked with everyday devices through the internet of things (IoT) [21]. IoT devices contain everyday objects, which communicate with each other to make life simpler for human beings [22]. IoT devices are increasingly used to produce vast amounts of data [23]. 5G networks will substantially develop the current IoT systems [24]. Edge computing has taken over cloud computing [25]. Ensuring appropriate requirements before deploying machine-type communications (MTC) applications can help scientists achieve Globally connected things [26].

Several studies have investigated the use, utility, and benefits of $5 \mathrm{G}$, but surprisingly very few investigated the need and interest of 5G in any region or country. In this paper, the need and interest of elevating to $5 \mathrm{G}$ were discussed in the context of Pakistan's mobile communication usage demographics. Previous studies associated with Pakistan have failed to demonstrate any significant contribution in this context.

The paper is organized as followed. Section 2 contains the currently available technologies, giving a brief discussion of current generations' technology, standards, and frameworks. Section 3 describes the limited use of currently prevailing technologies in terms of Pakistani demographics. Section 4 discusses the future interest of 5G in Pakistan, and lastly, the paper's conclusion is presented in Section 5.

\section{CURRENTLY AVAILABLE TECHNOLOGY}

In Pakistan, second, third and fourth generations (2G, 3G and $4 \mathrm{G})$, wireless network networks run simultaneously. Trials for $5 \mathrm{G}$ wireless networking have already begun. In the early $2000 \mathrm{~s}$, the telecom sector's deregulation happened, which boosted the industry and market competitiveness, notably [27].

\subsection{Second generation $(2 \mathrm{G})$}

Pakistan adopted the $2 \mathrm{G}$ in early 2000 when transmission of data, along with voice, was first accomplished through global system for mobile (GSM) networks [28]. After deregulation of the industry in 2003-04, the two multinational telecom companies telenor and warid started operations in 2005 [27]. General packet radio services (GPRS) followed as an advanced version. The $2 \mathrm{G}$ umbrella grew when the enhanced data GSM environment (EDGE, 2.75G) was introduced [29]. The problem of secure data transmission in 2G networks was achieved through digital encryption [30].

\subsection{Third generation (3G)}

Pakistan auctioned $3 \mathrm{G}$ spectrum in 2014 , where different telecom operators were issued $2 \times 10 \mathrm{MHz}$ and $2 \mathrm{xMHz}$ licensees from the $2100 \mathrm{MHz}$ band [31]. This generation addressed the various issues and shortcomings in previous generations [32]. As a critical variant, HSDPA (3.5G) enhanced the speed and data transmissions of the downlink data streams. Another option is HSUPA (3.75G) which improves the rate of uplink data streams.

\subsection{Fourth generation (4G)}

Pakistan auctioned 4G spectrum in 2014 and 2016. Only ZONG (Telecom operator) won the 4G license in the $1800 \mathrm{MHz}$ band in the first auction. In 2016, new licenses were auctioned by Pakistan telecommunication authority (PTA). Telenor was the sole winner with a $10 \mathrm{MHz}$ block [33]. In 4G, few modifications were introduced as compared to its predecessors [34]. The two commercially used and implemented 4G networks are cell WiMAX standard and long-term evolution (LTE) [35]-[37]. 4G paved the way for achieving high speed and real-time data streaming. 4G systems introduced MIMO technology. With this technology, users can have services that were previously impossible to experience [38]. 


\subsection{Fifth generation $(5 G)$}

$5 \mathrm{G}$ networking is supposed to address the currently faced problems adequately [8]. 5G mobile network technology triggers very high bandwidth usage for mobile users who never experienced such valuable technology. Networks using 5G will expand the current IoT and encourage cellular operations [24]. 5G technology comes with combinations of enhanced services and a wide range of connectivity [39]. Wireless technology's fifth-generation would be complete, tackling all urgent problems and have zero drawbacks [40]. However, with all these expectations, the adoption of 5G concepts requires quite a few infrastructural modifications [41] and up-gradation, which will come with significant expenses. Table 1 shows the comparison and differences among 3G, 4G and 5G networks in Pakistan [42]-[43].

Table 1. Comparison and differences among 3G, 4G, AND 5G networks

\begin{tabular}{|c|c|c|c|c|}
\hline $\begin{array}{l}\text { Technology/ } \\
\text { Feature }\end{array}$ & $2 \mathrm{G}$ & $3 \mathrm{G}$ & $4 \mathrm{G}$ & $5 \mathrm{G}$ \\
\hline Date of Introduction & 2003 & 2014 & 2014-16 & 2019-(trials) \\
\hline Data Bandwidth & $14.4 \mathrm{kbps}$ & 2Mbps & $2 \mathrm{Mbps}-1 \mathrm{Gbps}$ & $2 \mathrm{Mbps}-1 \mathrm{Gbps}$ \\
\hline Standards & $\begin{array}{l}\text { GSM, } \\
\text { GPRS, } \\
\text { EDGE }\end{array}$ & $\begin{array}{l}\text { WCDMA, UMTS, } \\
\text { CDMA2000, TD- } \\
\text { SCDMA }\end{array}$ & $\begin{array}{l}\text { All-access convergence including } \\
\text { OFDMA, LTE, WiMAX, MC- } \\
\text { CDMA Network-LMPS }\end{array}$ & $\begin{array}{l}\text { CDMA, BDMA, and } \\
\text { WWWW (Worldwide } \\
\text { Wireless Web), 5G NR }\end{array}$ \\
\hline Multiple Access & $\begin{array}{l}\text { FDMA, } \\
\text { TDMA }\end{array}$ & CDMA & CDMA & CDMA and BDMA \\
\hline Core Network & PSTN & packet network & All IP network & $\begin{array}{l}\text { Flatter IP network and } 5 \mathrm{G} \\
\text { network interfacing }(5 \mathrm{G}-\mathrm{NI})\end{array}$ \\
\hline
\end{tabular}

\section{LIMITED USE OF 2G, 3G AND 4G IN PAKISTAN}

In Pakistan, teledensity is as high as 76.377\% (Dec 2019) [44]. Still, wireless broadband penetration is currently only at $39.98 \%$ [10], [45]. That is equal to more than 169 million smartphone users, about 85 million 3G/4G customers, 3 million local fixed subscribers and about 87 million broadbands subscribers [45]. According to the investment board (BOI), in the last ten years, Pakistan has attained over $\$ 5.7$ billion in foreign investment in IT and telecommunications [46]. Although the number of broadband subscribers has exponentially increased since its launch in 2014, [47], adoption has been held back by non-infrastructural barriers [48], i.e. low smartphone adoption rate. Figure 1 [16, 47] compares mobile internet subscribers covered but not using the internet and users not included [16].

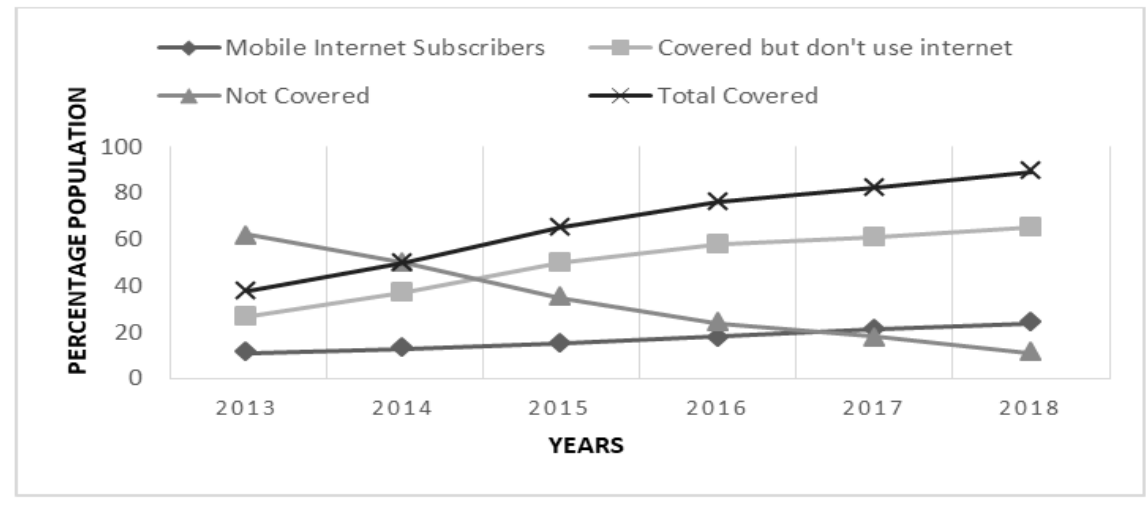

Figure. 1 Mobile broadband network coverage

The trends reveal that in the last five years between 2013 and 2018, wireless broadband coverage has dramatically improved from $38 \%$ to nearly $90 \%$. However, there is a significant gap between users and coverage, i.e., $50 \%$ of mobile users do not use mobile broadband even though the service is available. Only around 85 million users adopt mobile broadband technology. Similarly, the smartphone adoption rate is 37\% in Pakistan, compared to $48 \%$ in South Asia [16]. A large proportion of the subscribers (59\%) [45] avail themselves of 2G services. Percentages of connections (excluding cellular IoT) are illustrated in Figure 2 [16], [45]. 


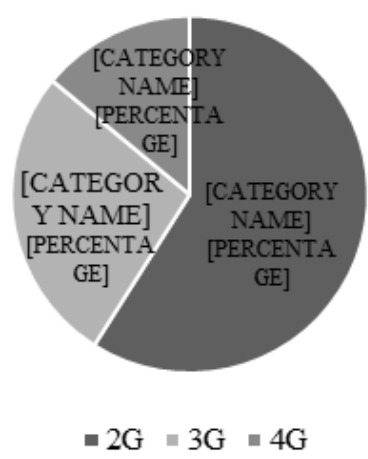

Figure 2. Percentage of connections $(2 \mathrm{G}, 3 \mathrm{G}, 4 \mathrm{G})$

However, mobile broadband's adoption rate over fixed broadband has substantially increased from 1.3 million to 87 million over the last few years [45]. Conversely, fixed broadband usage showed a dip from 3.8 million to 2.2 million over the same period [48]. Broadband users are illustrated in Figure 3 [16, 47].

Shortly, IoT will integrate into a variety of intelligent objects. IoT, as the hub between different technologies, will also allow various applications to make the intelligent decision [49]. At present, Pakistan's IoT applications have emerged in many applications. For example, solar home solutions make rural households off-grid power electronics, OBDs and IoT solutions integrated with vehicle and motorcycle insurances products to mitigate theft services [50]. A significant noticeable rise in the last two years from 400,000 to 662,000 connections [16] proves that IoT has a bright future in Pakistan. The rising will hugely depend on grasped intentions and ease of use of the IoT [50]. Figure 4 [16] illustrates the number of IoT cellular connections in Pakistan.

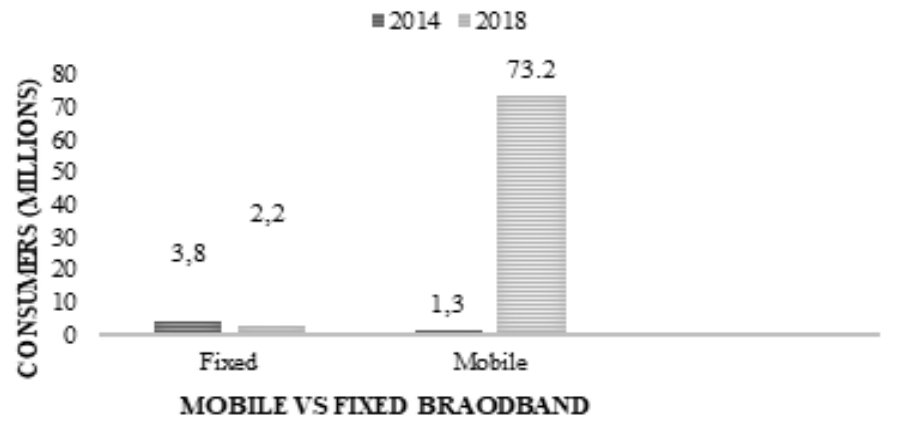

Figure 3. Fixed vs mobile broadband users in millions

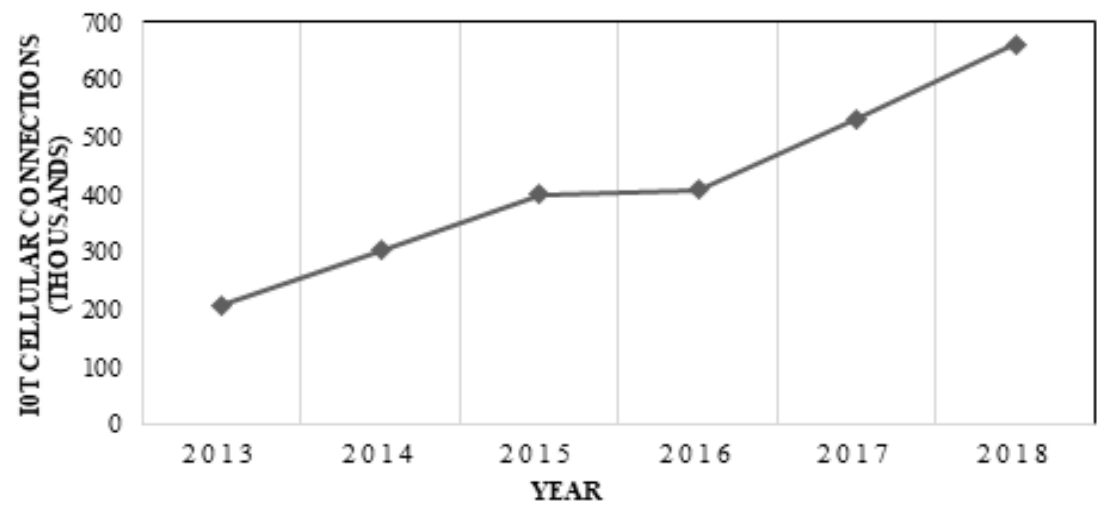

Figure 4. IoT Cellular connections in thousands 


\section{FUTURE INTEREST OF 5G IN PAKISTAN}

Pakistan introduced $3 \mathrm{G}$ and $4 \mathrm{G}$ cellular technologies in 2014. As depicted in Figure 3, 59\% of the total teledensity in Pakistan has not moved on from $2 \mathrm{G}$ connectivity. Only $27 \%$ of users have shifted to $3 \mathrm{G}$ technology, and a mere $14 \%$ of subscribers have adopted 4G technology [16]. The extrapolated percentages of the population for mobile broadband network coverage (2017-22) are calculated using MATLAB. These are illustrated in Figure 5.

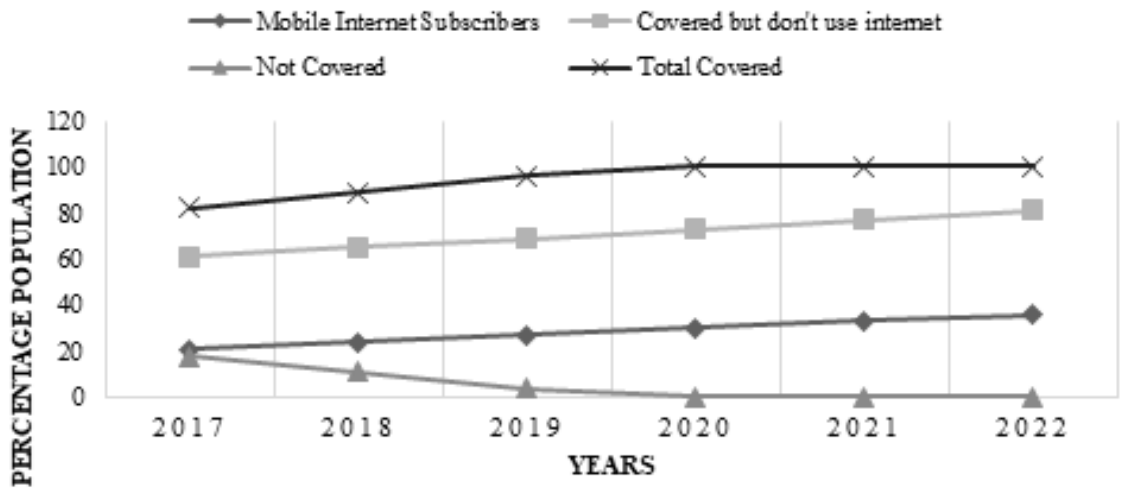

Figure 5. Extrapolated results for mobile broadband network coverage

These deduced results show that mobile broadband network coverage will reach $100 \%$ by next year. Still, it is worth noting that projections for mobile internet subscribers are only around $36 \%$. It means that a substantial proportion of $64 \%$ of the population will not use the internet regardless of coverage and spectrum availability. Despite over 9 million devices through local manufacturers since 2016 [16], the smartphone adoption rate is one of the lowest in the region. Pakistan will have around 146 million smartphone connections by 2025, lagging in the 8th position, while Indonesia, India, and China will be the smartphone superpowers over the same period [51]. Mobile internet subscribers in Pakistan are crouched, which profoundly questions the need for elevation to the fifth generation (5G) of mobile communication technology. Mobile penetration was incredibly enriched. After the launch of e-broadband in 2014, its penetration is incredibly rich and dramatically increased over the past few years. Based on the previous data, the MATLAB extrapolation tool was used to extrapolate the results, as shown in Figure 6.

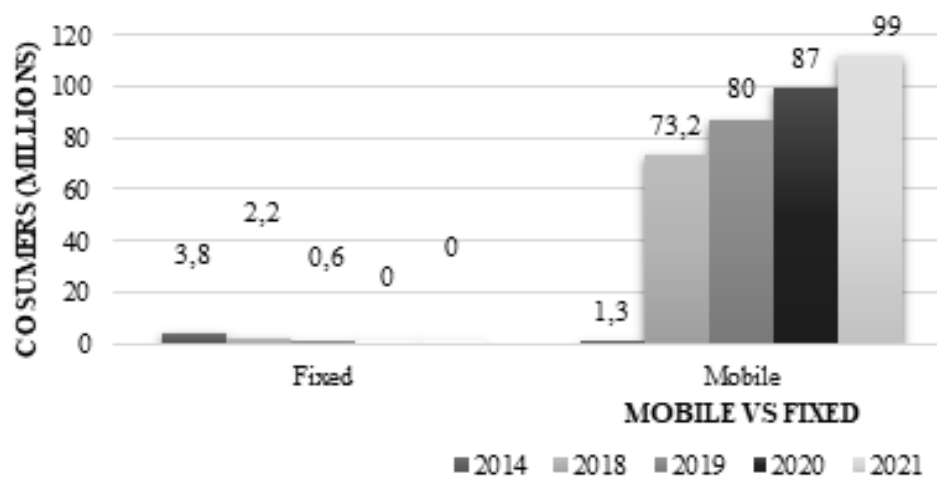

Figure 6. Foresee results for fixed vs mobile broadband users in Millions

The forecasted results and trends over the last two years imply that growth is reducing. The current reach is 87 million [45], and the estimated reach for mobile broadband users is 100 million by 2021, which is again not an encouraging figure for the adoption rate of mobile broadband. By 2025, smart cities in Pakistan will improve citizens' access to facilities such as smart energy, telemedicine, e-government, digital libraries and e-banking [12]. MATLAB extrapolation tool was used to extrapolate future trends for IoT mobile 
connections. Figure 7 illustrates the results, which are encouraging but are not satisfying enough for the embracement of $5 \mathrm{G}$.

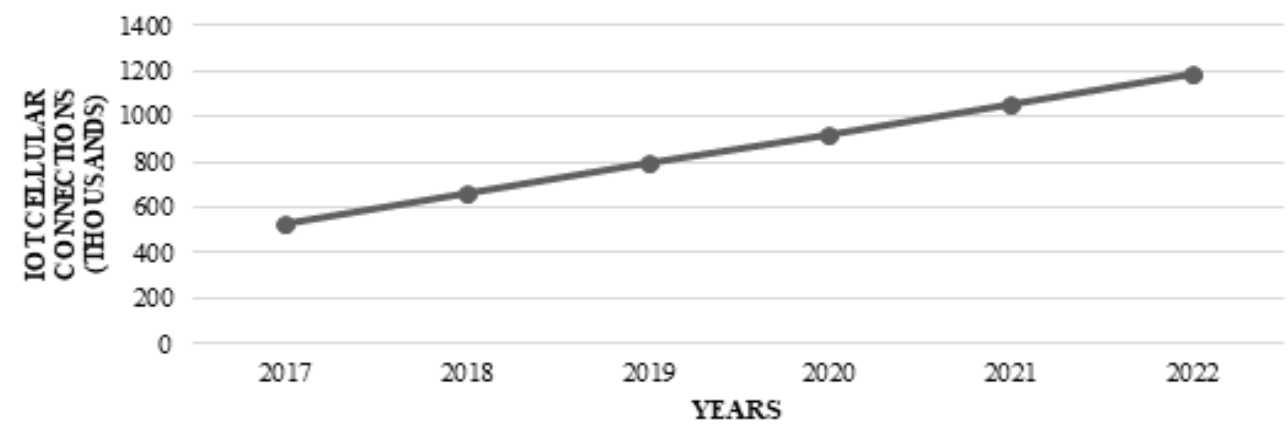

Figure 7. IoT Cellular connections in thousands (predictions)

Currently, there are over 9.1 billion IoT connections worldwide, and 16 billion additional links are expected by 2025, making it a significant number of 25.2 billion. Smart buildings, consumer electronics, and smart homes are the key growth verticals in today's age [51]. The time has come for Pakistan to be on-board with these trends.

\section{CONCLUSION}

In this paper, the prevalence of $2 \mathrm{G}, 3 \mathrm{G}$, and $4 \mathrm{G}$ mobile communication scenarios in the demographics and challenges faced in Pakistan were studied and reviewed. In Pakistan, the adoption rate for switching to $3 \mathrm{G}, 4 \mathrm{G}$ is not encouraging. $2 \mathrm{G}$ networks still hold $59 \%$ of the total subscribers. The smartphone adoption rate is also low despite the introduction of local manufacturing and mobile devices' production. Pakistan is likely to miss the chance of being the smartphone superpower like China, India, and Indonesia are all set to meet their set targets by 2025. Also, an essential aspect of 5G mobile communication technology is cellular IoT connections. Current numbers and future extrapolations are also not promising. They need to rise exponentially to fill the spectrum. The study revealed that non-infrastructural barriers influence the low adoption rate, which is the main reason behind the spectrum utilization gap, i.e., the use of $3 \mathrm{G}$, and the $4 \mathrm{G}$ spectrum is minimal. Lacking behind in literacy and shortage of jobs are the main contributor to such trends. It is favourable to fill up the spectrum utilization gap before elevation to $5 \mathrm{G}$, which may be considered a fancier operation. The government can Introduce the time-bound frameworks for gap filling, consumer readiness, infrastructural adjustments, and up-gradation. The proposed exercise will facilitate the elevation to the $5 \mathrm{G}$ of mobile communication technology at the right time. 7In the future, both qualitative and quantitative studies can be carried out to get a deeper pulse of reasons behind non-infrastructural barriers. Studies can also dig deeper into the proposed frameworks for gap filling, consumer readiness, infrastructural adjustments, and up-gradation.

\section{ACKNOWLEDGEMENTS}

This study was funded through UTM Research Grant-R. K130000.2656.18J05 and UTM Research Grant-Q. K130000.3556.06J45.

\section{REFERENCES}

[1] E. Abderraouf, A. Bassou, and M. R. Lahcene, "Higher performance and lower complexity turbo decoding scheme for 4G-LTE using unpunctured turbo trellis-coded modulation," Indonesian Journal of Electrical Engineering and Computer Science (IJEECS), vol. 18, no. 1, pp. 351-360, 2020, doi: 10.11591/ijeecs.v18.i1.pp351-360.

[2] M. A. Almaiah, Z. Dawahdeh, O. Almomani, A. Alsaaidah, A. Al-khasawneh, and S. Khawatreh, "A new hybrid text encryption approach over mobile ad hoc network," International Journal of Electrical and Computer Engineering (IJECE), vol. 10, no. 6, pp. 6461-6471, 2020, doi: 10.11591/ijece.v10i6.pp6461-6471.

[3] M. E. Bayrakdar, "Cooperative communication based access technique for sensor networks," International Journal of Electronics, vol. 107, no. 2, pp. 212-225, 2020, doi: 10.1080/00207217.2019.1636313. 
[4] A. Singh, "A review of different generations of mobile technology," International Journal of Advanced Research in Computer Engineering and Technology (IJARCET), vol. 4, no. 8, pp. 3404-3408, 2015.

[5] A. A. Ibrahim and F. Hashim, "An architecture of 5G based on SDN NV wireless network," Indonesian Journal of Electrical Engineering and Computer Science (IJEECS), vol. 14, no. 2, pp. 724-733, 2019, doi: 10.11591/ijeecs.v14.i2.pp725-734.

[6] F. Saeed, N. Gazem, F. Mohammed, and A. Busalim, "Recent Trends in Data Science and Soft Computing, Proceedings of the 3rd International Conference of Reliable Information and Communication Technology (IRICT 2018). Springer, 2018.

[7] C. Wang et al., "Cellular architecture and key technologies for 5G wireless communication networks," IEEE Communications Magazine, vol. 52, no. 2, pp. 122-130, 2014, doi: 10.1109/MCOM.2014.6736752.

[8] B. Vani and R. Sundaraguru, "Insights on Significant Implication on Research Approach for Enhancing 5G Network System," Indonesian Journal of Electrical Engineering and Informatics (IJEEI), vol. 7, no. 3, pp. 586598, 2019.

[9] I. F. Akyildiz, S. Nie, S.-C. Lin, and M. Chandrasekaran, "5G roadmap: 10 key enabling technologies," Computer Networks, vol. 106, pp. 17-48, 2016, doi: 10.1016/j.comnet.2016.06.010.

[10] P. T. Authority, "ANNUAL REPORT," 2018, Available: https://www.pta.gov.pk/.

[11] S. Y. Imtiaz, M. A. Khan, and M. Shakir, "Telecom sector of Pakistan: Potential, challenges and business opportunities," Telematics and Informatics, vol. 32, no. 2, pp. 254-258, 2015, doi: 10.1016/j.tele.2014.09.002.

[12] M. Khan, S. Yasir, S. Khan, and M. Shakir, "Deployment of 3g/4g Technologies In Pakistan," Journal Of The Institute of Telecommunications Professionals, vol. 11, pp. 28-32, 2017.

[13] T. Arshad, M. F. Awan, T. Ahmad, and S. Qaisar, "Performance Evaluation of Mobile Broadband Cellular Networks in Pakistan," in 2016 IEEE 41st Conference on Local Computer Networks Workshops (LCN Workshops), pp. 104-111: IEEE, 2016.

[14] H. Plecher, "Unemployment rate in Pakistan 2018," 2019, Available: https://www.statista.com/statistics/383735/unemployment-rate-in-pakistan/.

[15] A. Yusufzai, "Latest Economic Survey Shows a Higher Literacy Rate and Educational Expenditure," 2019, Available: https://propakistani.pk/2019/06/10/latest-economic-survey-shows-a-higher-literacy-rate-and-educational-expenditure/.

[16] L. A. Kenechi Okeleke, GSMA Intelligence, "The power of mobile to accelerate digital transformation in Pakistan," 2019, Available: https://www.gsma.com/

[17] T. A. M. F. Awan, S. Qaisar, N. Feamster and S. Sundaresan, "Me The power of mobile to accelerate digital transformation in Pakistan The power of mobile to accelerate digital transformation in Pakistan The power of mobile to accelerate digital transformation in Pakistan asuring broadband access network performance in Pakistan: A comparative study," in IEEE 40th Local Computer Networks Conference Workshops (LCN Workshops), pp. 595602: IEEE, 2015.

[18] A. M. Al-samman, M. H. Azmi, and T. A. Rahman, "A Survey of Millimeter Wave (mm-Wave) Communications for 5G: Channel Measurement Below and Above $6 \mathrm{GHz}, "$ in International Conference of Reliable Information and Communication Technology, 2018, pp. 451-463: Springer, doi: 10.1007/978-3-319-99007-1_43.

[19] F. Boccardi, R. W. Heath, A. Lozano, T. L. Marzetta, and P. Popovski, "Five disruptive technology directions for 5G," IEEE Communications Magazine, vol. 52, no. 2, pp. 74-80, 2014, doi: 10.1109/MCOM.2014.6736746.

[20] K. Luechaphonthara and A. Vijayalakshmi, "IOT based application for monitoring electricity power consumption in home appliances," International Journal of Electrical and Computer Engineering (IJECE), vol. 9, no. 6, p. 4988, 2019, doi: 10.11591/ijece.v9i6.pp4988-4992.

[21] A. H. Ali, A. H. Duhis, N. A. L. Alzurfi, and M. J. Mnati, "Smart monitoring system for pressure regulator based on IOT," International Journal of Electrical and Computer Engineering (IJECE), vol. 9, no. 5, pp. 3450-3456, 2019, doi: 10.11591/ijece.v9i5.pp3450-3456.

[22] A. Wani and S. Revathi, "Ransomware protection in loT using software defined networking," International Journal of Electrical \& Computer Engineering (IJECE) (2088-8708), vol. 10, 2020, doi: 10.11591/ijece.v10i3.pp3166-3175.

[23] C. N. Tadros, M. R. M. Rizk, and B. M. Mokhtar, "Software Defined Network-Based Management for Enhanced 5G Network Services," IEEE Access, vol. 8, pp. 53997-54008, 2020, doi: 10.1109/ACCESS.2020.2980392.

[24] A. C. Oliver, "How IoT \& Industry 4.0 Relate-and Why Manufacturers Should Care," in lucidworks vol. 2020, ed, 2018.

[25] Y. Mao, C. You, J. Zhang, K. Huang, and K. B. Letaief, "A survey on mobile edge computing: The communication perspective," IEEE Communications Surveys \& Tutorials, vol. 19, no. 4, pp. 2322-2358, 2017, doi: 10.1109/COMST.2017.2745201.

[26] G. A. Akpakwu, B. J. Silva, G. P. Hancke, and A. M. Abu-Mahfouz, "A survey on 5G networks for the Internet of Things: Communication technologies and challenges," IEEE Access, vol. 6, pp. 3619-3647, 2017. doi: 10.1109/ACCESS.2017.2779844.

[27] S. Latif and M. Munir, "Challenges been faced by Mobile Operators in Pakistan for transition from $2 \mathrm{G}$ to $3 \mathrm{G} \& 4 \mathrm{G}$ Mobile Services," Journal Of Mechanics of Continua And Mathematical Sciences, vol. 13, pp. 198-207, 11/11 2018.

[28] Q. K. U. D. Arshad, A. U. Kashif, and I. M. Quershi, "A Review on the Evolution of Cellular Technologies," in 2019 16th International Bhurban Conference on Applied Sciences and Technology (IBCAST), pp. 989-993: IEEE, 2019, doi: 10.1109/IBCAST.2019.8667173.

[29] R. Yadav, "Challenges and evolution of next generations wireless communication," in Proceedings of the International MultiConference of Engineers and Computer Scientists, vol. 2, 2017.

[30] R. Sood and A. Garg, "Digital society from 1G to 5G: a comparative study," International Journal of Application or Innovation in Engineering \& Management (IJAIEM), vol. 3, no. 2, pp. 186-193, 2014. 
[31] P. Aggarwal and P. Arora, "Neha Migration from 2g to 4g mobile technology," Advance in Electronic and Electric Engineering, RIP, vol. 3, pp. 1251-1264, 2013.

[32] S. Jaiswal, A. Kumar, and N. Kumari, "Development of wireless communication networks: From 1G to 5G," International Journal of Engineering and Computer Science, vol. 3, no. 5, pp. 6053-6056, 2014.

[33] D. Balasubramanian, "QoS in cellular networks," Tech. Rep., 2006.

[34] U. Varshney, "4G wireless networks," IT Professional, vol. 14, no. 5, pp. 34-39, 2012.

[35] A. Mehbodniya, F. Kaleem, K. K. Yen, and F. Adachi, "Wireless network access selection scheme for heterogeneous multimedia traffic," IET networks, vol. 2, no. 4, pp. 214-223, 2013, doi: 10.1109/CCNC.2013.6488487.

[36] D. Lopez-Perez, A. Valcarce, G. De La Roche, and J. Zhang, "OFDMA femtocells: A roadmap on interference avoidance," IEEE communications magazine, vol. 47, no. 9, pp. 41-48, 2009, doi: 10.1109/MCOM.2009.5277454.

[37] S. A. Alomari, M. S. Alzboon, M. S. Al-Batah, and B. Zaqaibeh, "A novel adaptive schema to facilitates playback switching technique for video delivery in dense LTE cellular heterogeneous network environments," International Journal of Electrical \& Computer Engineering (IJECE) (2088-8708), vol. 10, no. 5, 2020, doi: 10.11591/ijece.v10i5.pp5347-5367.

[38] H. Kaushik, S. Chaudhary, N. Singh, and K. K. Verma, "Advance Handoff Requirements Schemes in Wimax and LTE Networks in Wireless Sensor Network," International Journal of Computer Applications, vol. 975, p. 8887, 2012.

[39] S. Hong et al., "Applications of self-interference cancellation in 5G and beyond," IEEE Communications Magazine, vol. 52, no. 2, pp. 114-121, 2014, doi: 10.1109/MCOM.2014.6736751.

[40] S. Kumar, G. Gupta, and K. R. Singh, "5G: Revolution of future communication technology," in 2015 International Conference on Green Computing and Internet of Things (ICGCIoT), pp. 143-147, IEEE, 2015, doi: 10.1109/ICGCIoT.2015.7380446.

[41] B. Naeem, R. Ali, B. Shabbir, and K. Ali, "5G-The Expectations and Enablers," Proceedings of the Pakistan Academy of Sciences: A. Physical and Computational Sciences, vol. 55, no. 3, pp. 11-20-11-20, 2018.

[42] M. A. Albreem, "5G wireless communication systems: Vision and challenges," in 2015 International Conference on Computer, Communications, and Control Technology (I4CT), pp. 493-497, IEEE, 2015, doi: 10.1109/I4CT.2015.7219627.

[43] K. Khurshid and I. A. Khokhar, "Comparison survey of 4G competitors (OFDMA, MC CDMA, UWB, IDMA)," in 2013 International Conference on Aerospace Science \& Engineering (ICASE), pp. 1-7: IEEE, 2013, doi: 10.1109/ICASE.2013.6785555.

[44] CEIC, "Pakistan Teledensity: Mobile," 2019, Available: https://www.ceicdata.com/

[45] P. T. A. (PTA). Telecom Indicators [Online]. Available: https://www.pta.gov.pk/

[46] (2018). Pakistan Telecommunication Authority, Annual Report 2016-2018.

[47] P. T. Authority. Telecom Indicators [Online]. Available: https://www.pta.gov.pk

[48] L. A. Jan Stryjak and M. E. S. Henry James, "Country overview: Pakistan A digital future," 2016, Available: https://www.gsmaintelligence.com/research/.

[49] S. H. Shah and I. Yaqoob, "A survey: Internet of Things (IOT) technologies, applications and challenges," in 2016 IEEE Smart Energy Grid Engineering (SEGE), pp. 381-385: IEEE, 2016, doi: 10.1109/SEGE.2016.7589556.

[50] A. A. M. Laeeq-ur-Rehman, Javed Ferzund, Ateeq-ur-Rehman, "Acceptance of IoT in Pakistan: A Survey " Journal of Computer Science IJCSIS, vol. 15, no. 5, 2017.

[51] GSMA, "The Mobile Economy 2019," 2019, Available: https://www.gsmaintelligence.com/research/. 